\title{
The Relationship between Aggressiveness and Gender in Patients with Temporal Lobe Epilepsy
}

\author{
Olga V. Vorob'eva, Julia I. Stadnyuk \\ Sechenov First Moscow State Medical University, Moscow, Russia \\ Email:transjulia@mail.ru
}

How to cite this paper: Vorob'eva, O.V. and Stadnyuk, J.I. (2016) The Relationship between Aggressiveness and Gender in Patients with Temporal Lobe Epilepsy. World Journal of Neuroscience, 6, 227-235. http://dx.doi.org/10.4236/wjns.2016.64028

Received: July 22, 2016

Accepted: October 9, 2016

Published: October 12, 2016

Copyright $\odot 2016$ by authors and Scientific Research Publishing Inc. This work is licensed under the Creative Commons Attribution International License (CC BY 4.0).

http://creativecommons.org/licenses/by/4.0/

\begin{abstract}
Purpose: To examine the impact of gender and social gender on the level and typology of interictal aggressiveness in patients with temporal lobe epilepsy. Material and Methods: 40 adult patients with Temporal Lobe Epilepsy (TLE) and 86 healthy individuals were included. The qualitative and quantitative aggressiveness assessment was made with Buss-Durkee Hostility Inventory. The gender role behavior was measured with Bem Sex Role Inventory. Results: Patients with TLE didn't differ from healthy subjects on the total scores of motor and attitudinal hostility components, but scored higher on subscales "resentment" and "guilt". The comparative gender analysis showed there were no phenomenological differences in people with TLE. Assault dominated in healthy male subjects, resentment-in healthy female subjects. The prevalence of feminine social gender type was significantly higher in people with TLE in comparison to healthy people ( $55 \%$ vs. $26 \%, \mathrm{p}<0.01$ ). In patients with TLE, the number of masculine traits positively correlated with indirect hostility subscale and attitudinal hostility component scores. In healthy subjects, the masculine traits positively correlated with assault.
\end{abstract}

\section{Keywords}

Temporal Lobe Epilepsy, Interictal Aggressiveness, Typology of Interictal Aggressiveness, Gender, Social Gender

\section{Introduction}

The relationship between epilepsy and aggressiveness is a particularly controversial issue. For example, a multicenter Italian study, which used the standardized test Aggression Questionnaire, showed that the level of interictal aggressiveness in people with epilepsy was even lower than that in healthy subjects [1]. At the same time, communitybased studies show that aggressive behavior is typical for some groups of people with 
epilepsy (McDermott, 1995; Seo et al., 2015). Not well studied is the relationship between aggressiveness and personality traits in patients with epilepsy. The aim of our study was to estimate the influence of sex and gender characteristics on the level and typology of interictal aggressiveness in patients with Temporal Lobe Epilepsy (TLE).

\section{Material and Methods}

The clinical and psychological investigation was organized as a simple open study of 40 patients of Caucasian race with temporal lobe epilepsy aged from 19 to 65 years old. The diagnosis of epilepsy was made according to the guidelines of International League Against Epilepsy (ILAE). The clinical characteristics, EEG and MRI/CT findings were compatible with temporal lobe epilepsy. All patients didn't have any history of drug or alcohol abuse and any mental diseases. The main demographic and clinical characteristics of our study population are presented in Table 1.

The control group consisted of 86 healthy subjects ( 40 male and 46 female) aged from 21 to 62 years, and was comparable to the main group on age and gender (Table 2). All members of the control group didn't have any history of serious diseases or other neurological disorders, any history of drug or alcohol abuse, any lifetime psychiatric

Table 1. Demographic and clinical characteristics of the study population.

\begin{tabular}{|c|c|}
\hline Characteristic & Value \\
\hline \multicolumn{2}{|l|}{ Age (years) } \\
\hline Mean \pm SD & $38.63 \pm 12.3$ \\
\hline Gender(male/female) $(\mathrm{n}=)$ & $18 / 22$ \\
\hline Occupational status (employed/unemployed) (\%) & $58 / 42$ \\
\hline Marital status (nonsingle/single) (\%) & $55 / 45$ \\
\hline Education (higher education/other) (\%) & $63 / 37$ \\
\hline \multicolumn{2}{|l|}{ Age at onset of seizures (years) } \\
\hline Mean \pm SD & $24.48 \pm 14.2$ \\
\hline \multicolumn{2}{|l|}{ Disease duration (years) } \\
\hline Mean \pm SD & $14.18 \pm 11.78$ \\
\hline \multicolumn{2}{|l|}{ Seizure type, \% } \\
\hline CPS only & 5 \\
\hline CPS/GTCS & 15 \\
\hline SPS/CPS & 33 \\
\hline SPS/CPS/GTCS & 15 \\
\hline GTCS only & 12 \\
\hline SPS/GTCS & 20 \\
\hline Seizure frequency in previous month (3 and more/less than 3 ) (\%) & $50 / 50$ \\
\hline Patients, which report about any individual seizure triggers (\%) & 70 \\
\hline $\begin{array}{l}\text { The laterality of epileptogenic focus (EEG-findings) (left } \\
\text { hemishere/right hemishere) (\%) }\end{array}$ & $43 / 45$ \\
\hline Number of medications (monotherapy/polytherapy) (\%) & $43 / 55$ \\
\hline Disability status (yes/no)\% & $33 / 67$ \\
\hline
\end{tabular}


Table 2. The comparison of main and control group on age and gender.

\begin{tabular}{cccc}
\hline & $\begin{array}{c}\text { Patients with temporal lobe } \\
\text { epilepsy }(\mathrm{n}=40)\end{array}$ & Control group $(\mathrm{n}=86)$ & Sig., 2-tailed \\
\hline $\begin{array}{c}\text { Age (years) } \\
\text { Mean } \pm \text { SD } \\
\text { Male (\%) }\end{array}$ & $38.63 \pm 12.25$ & $35.97 \pm 10.99$ & $\mathrm{P}=0.23$ \\
\hline
\end{tabular}

disorders.

All participants provided written informed consent before the investigation. All participants were fully capable to understand and comprehend the instructions.

To measure the gender role behavior all patients were asked to fill Bem Sex Role Inventory (1974) [2]. It consists of 60 different personality traits, 20 masculine, 20 feminine, and 20 filler traits thought to be gender neutral. Finally Bem Index was calculated using following formula:

$$
I S=(F-M) * 2.322,
$$

where $F$ is a number of female traits divided by $20, M$ is a number of male traits divided by 20 . The Bem index (IS) was used to divide patients into 6 subgroups:

Feminine women $-I S \geq 0.81$;

Masculine women $-I S \leq-0.235$;

Feminine men $-I S \geq 0.235$;

Masculine men $-I S \leq-0.81$;

Androgynous patients $-I S \geq 0$;

Undifferentiated patients $-I S<0$.

The qualitative and quantitative assessment of aggressiveness was made using BussDurkee Hostility Inventory (BDHI) [3]. Each of 8 subscales (Assault, Indirect Hostility, Irritability, Negativism, Resentment, Suspicion, Verbal Hostility, and Guilt), the scores of attitudinal (the sum of Resentment and Suspicion scores) and motor (the sum of Assault, Indirect Hostility and Verbal Hostility) component of hostility were calculated.

Depression and anxiety levels were accessed using Hospitality Anxiety and Depression Scale (HADS) [4]-[6].

The statistical analysis was carried out using SPSS 18.0. Parametric and nonparametric methods were used. To compare the quantitative characteristics of all scales Independent Samples t-test was used, the nominal variables were estimated with chi-square criterion.

\section{Results}

\subsection{The Impact of Gender on Aggressiveness Level in Temporal Lobe Epilepsy}

The main group did not differ from healthy subjects on motor and attitudinal hostility score. At the same time patients with TLE had a higher Resentment and Guilt scores in comparison to healthy subjects. The mean level of anxiety and depression in people 
with TLE was normal, but significantly higher than in healthy people (Table 3). 15\% of patients had mild anxiety according to HADS (8 - 10 p.), 18\% had moderate anxiety (11 - 14 p.), $3 \%$ had severe anxiety (15 - 21 p.). 13\% of patients had subclinical depression (8 - 10 p.), 3\% had moderate depression (11 - 14 p.).

The comparison analysis of aggressiveness, anxiety and depression in males and females of main and control groups is showed in Table 4. The aggressiveness level on subscale Assault was higher in subgroup of healthy males in comparison to in healthy females $(p<0.001)$. At the same time the Resentment score in healthy women was higher than in healthy men $(\mathrm{p}<0.01)$ (Table 4). This result is the same as in previous studies (Coie \& Dodge, 1997; Maccoby \& Jacklin, 1974; Frey et al., 2003). On the opposite, our analysis didn't reveal any significant gender differences in interictal hostility in people with TLE.

Females with TLE didn't have any significant differences from healthy females on motor and attitudinal components of hostility and scored higher on Guilt. Males with epilepsy scored higher on resentment and guilt and on attitudinal component of hostility than healthy males $(\mathrm{p}<0.05)$ (Table 4$)$.

It was showed that anxiety level of main group was significantly higher in women than in men with TLE. There were no such differences in control group. The cohort of females with TLE had a 2-fold higher anxiety and depression level compared to healthy females. There were no such differences in male population (Table 4).

\subsection{The Impact of Gender Role Behavior on Aggressiveness Level in Temporal Lobe Epilepsy}

According to the aim of our study we examined the type of gender role behavior in

Table 3. Aggressiveness, anxiety and depression in patients with temporal lobe epilepsy and healthy subjects.

\begin{tabular}{cccc}
\hline & $\begin{array}{c}\text { Patients with temporal } \\
\text { lobe epilepsy }(\mathbf{n}=40)\end{array}$ & $\begin{array}{c}\text { Control group } \\
(\mathbf{n}=\mathbf{8 6})\end{array}$ & Sig.2-tailed \\
\hline Assault & $4.25 \pm 2.47$ & $4.05 \pm 1.88$ & $\mathrm{NS}$ \\
Verbal Hostility & $6.25 \pm 3.04$ & $6.01 \pm 2.24$ & $\mathrm{NS}$ \\
Indirect Hostility & $4.55 \pm 1.62$ & $4.53 \pm 1.65$ & $\mathrm{NS}$ \\
Negativism & $2.17 \pm 1.68$ & $1.66 \pm 1.35$ & $\mathrm{NS}$ \\
Irritability & $4.50 \pm 2.27$ & $4.16 \pm 2.27$ & $\mathrm{NS}$ \\
$\quad \begin{array}{c}\text { Suspicion } \\
\text { Resentment }\end{array}$ & $3.37 \pm 2.08$ & $3.10 \pm 2.22$ & $\mathrm{NS}$ \\
$\quad$ Guilt \\
** & $3.95 \pm 1.52$ & $2.95 \pm 1.47$ & $\mathrm{P}=0.001$ \\
Motor component of & $6.13 \pm 1.38$ & $5.08 \pm 1.65$ & $\mathrm{P}=0.001$ \\
hostility & $14.80 \pm 5.49$ & $14.51 \pm 4.29$ & $\mathrm{NS}$ \\
Attitudinal component & & & $\mathrm{NS}$ \\
of hostility & $7.23 \pm 3.28$ & $6.05 \pm 3.26$ & $\mathrm{p}<0.001$ \\
Anxiety* & $6.78 \pm 4.10$ & $4.53 \pm 2.26$ & $\mathrm{p}=0.017$ \\
Depression & $4.53 \pm 3.02$ & $3.36 \pm 2.24$ &
\end{tabular}

${ }^{*} \mathrm{p}<0.05,{ }^{* *} \mathrm{p}<0.01$. 
Table 4. The impact of gender on aggressiveness, anxiety and depression in patients with temporal lobe epilepsy and healthy subjects.

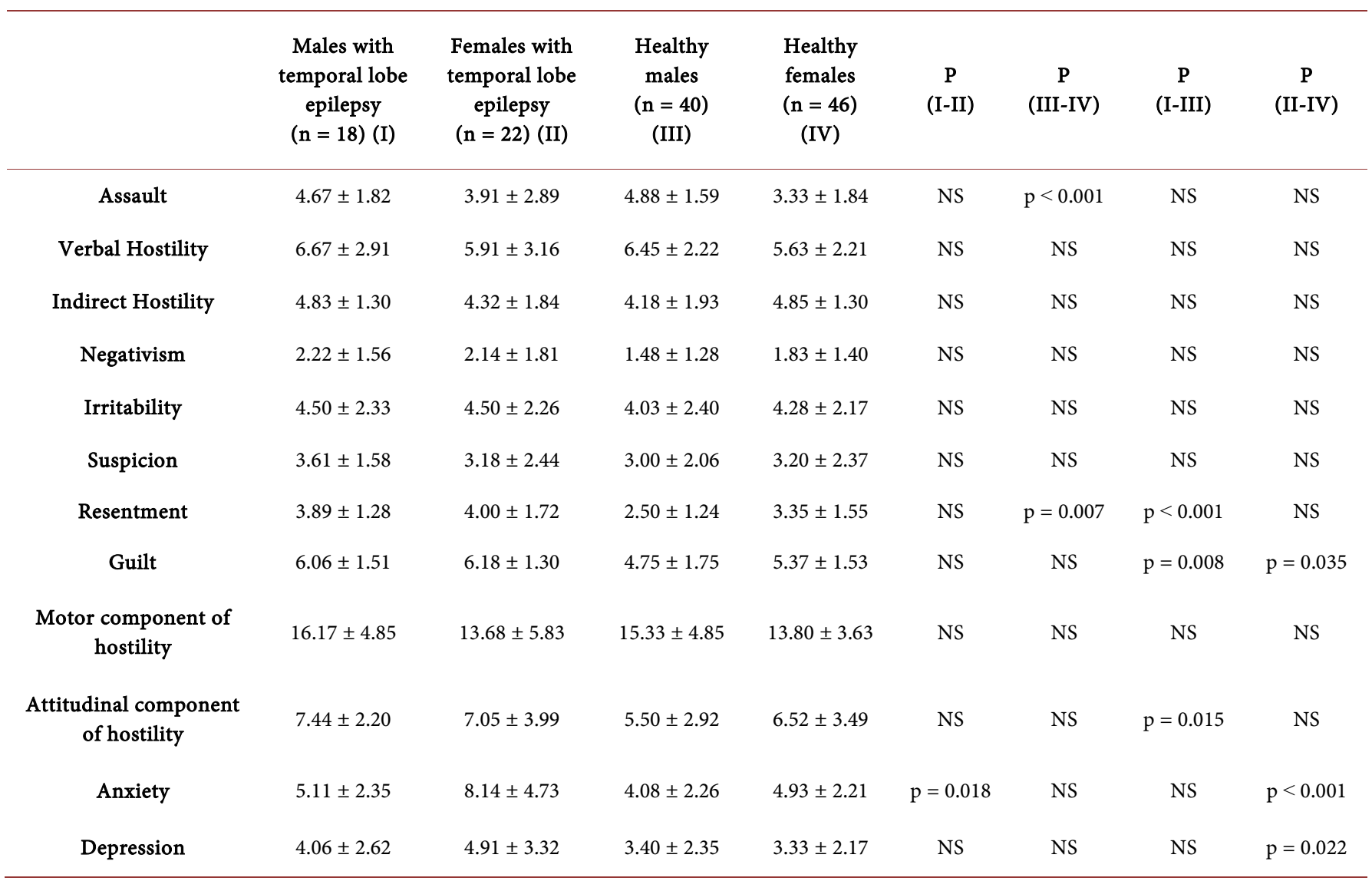

main and control group. We revealed that 22 of our patients (55\%) were feminine, 3 (8\%) masculine, 9 (23\%) androgynous, 6(15\%) undifferentiated. In the control group $22(26 \%)$ were feminine, 9 (10\%) masculine, 34 (40\%) androgynous, 21 (24\%) undifferentiated. So the dominant gender in the healthy population was androgynous type, in people with TLE-feminine type. The prevalence of feminine gender in people with TLE was higher than in healthy subjects $\left(\chi^{2}=10.397, \mathrm{p}<0.01\right)$. The gender role behavior of males and females with TLE and healthy subjects is presented in Figure 1.

The correlation analysis was conducted between the HADS, Buss-Durkee Hostility Inventory, Bem Sex role inventory scores in main and control group. In healthy people the number of masculine traits is inspected as positively correlated with motor component of hostility including Assault and Verbal Hostility (Table 5). There were wider correlations between masculine trait number and aggressiveness profile in patients with TLE. They had not only positive correlation between masculine trait number and motor hostility score (including Verbal Hostility and Irritability) typical for healthy individuals, but also positive correlation between masculine trait number and attitudinal component including the Suspicion subscale and Negativism (Table 6). Unlike patients with TLE in healthy individuals' feminine trait number positively correlated with Guilt and negatively-with Negativism. 


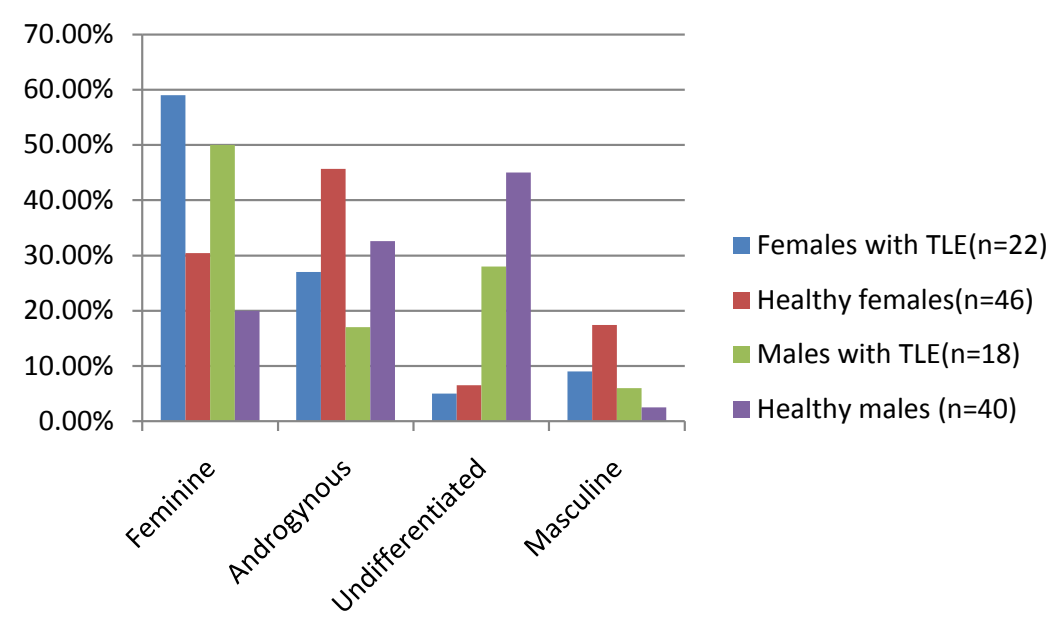

Figure 1. The gender role behavior of males and females with TLE and healthy subjects. The comparative analysis of males with TLE and healthy males showed that feminine type of gender role behavior dominated in males with TLE and undifferentiated type-in healthy males. The comparative analysis of females with TLE and healthy females showed that feminine type of gender role behavior dominated in females with TLE and androgynous type-in healthy females. The prevalence of feminine gender in males and females with TLE was higher than in healthy males and females $(\mathrm{p}<0.05)$.

\section{Discussion}

Our study showed that people with TLE didn't differ from healthy people on motor and attitudinal components of hostility. This means that their aggressiveness is within the social norm. This result is the same as in previous studies [7]-[10]. But subjects with TLE scored higher than healthy people on Resentment and Guilt subscales which indicates that mostly the self-directed emotional component of hostility is involved.

The comparative gender analysis showed that there are no gender differences in people with TLE. This fact differs patients with TLE from healthy population, which is characterized by high Assault score in males (Coie \& Dodge, 1997; Maccoby \& Jacklin, 1974; Frey et al., 2003) and high covert aggressiveness score in females (Archer, 2004; Card, Stucky, Sawalani, \& Little, 2008). The comparison between male subpopulation of patients with TLE and healthy men showed that the high attitudinal hostility component in people with TLE is due to males with TLE. High attitudinal hostility component with high Resentment score and high Guilt score is typical for males with TLE. The aggressiveness pattern of females with TLE didn't differ from healthy female individuals. To conclude, aggressiveness pattern of males with TLE gets closer to female type and gender differences in aggressiveness disappear in people with TLE.

A very important fact showed in the study is that the prevalence of different social gender types is different in healthy subjects and people with TLE. While androgynous type is typical for the healthy population, the most common social gender type for people with TLE is a feminine gender. The feminine gender dominated not only in male but also in female subgroup of patients with TLE. A lot of researchers suggest the presence of gender role conflicts and that the coping style is based on gender role behavior. 
Table 5. Correlation between gender role characteristics and aggressiveness, anxiety and depression level in healthy people.

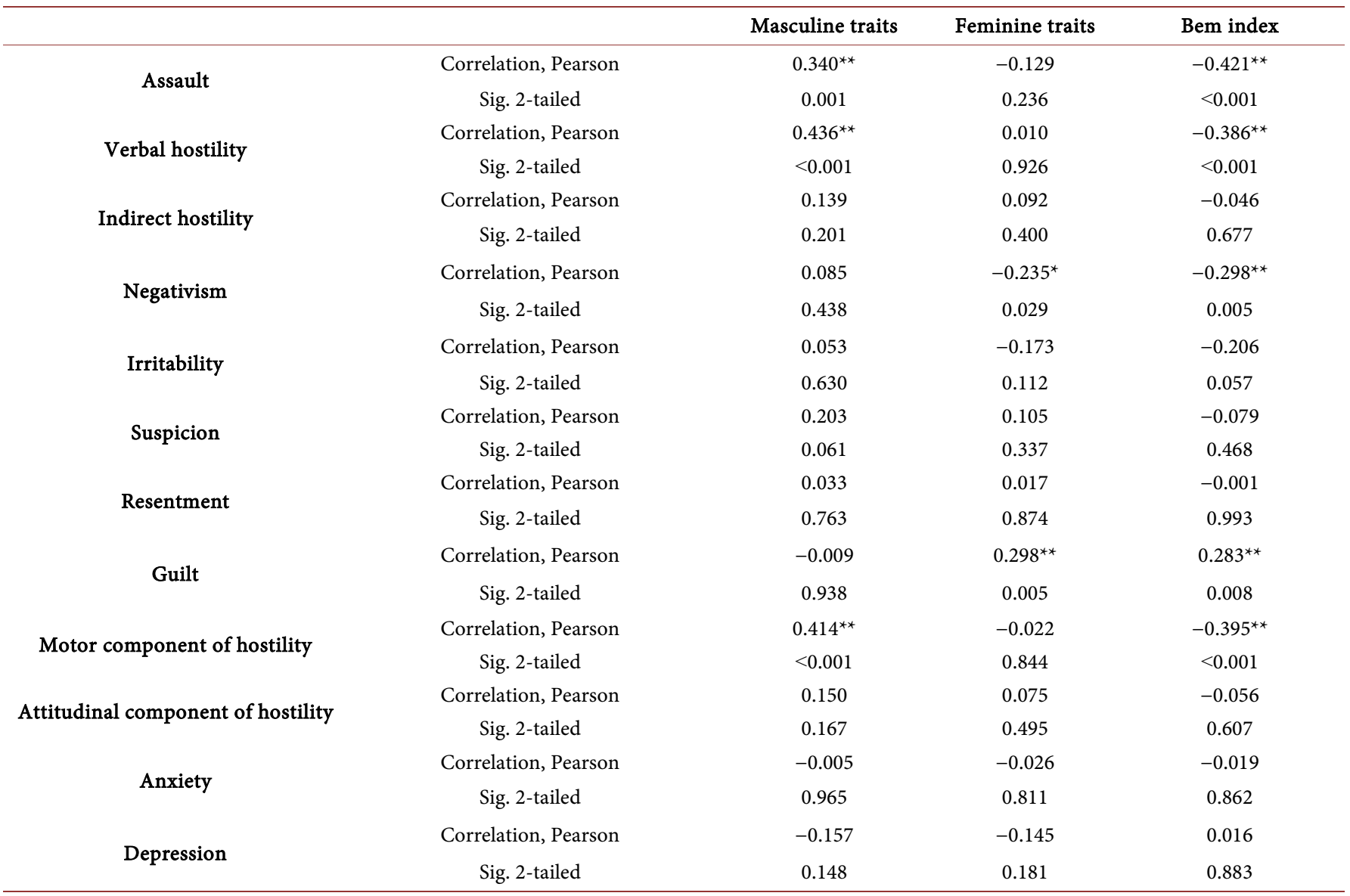

${ }^{*} \mathrm{p}<0.05,{ }^{* *} \mathrm{p}<0.01$.

Mental health is based on a balance of masculine and feminine traits. The dominating gender type in healthy people is androgynous which consists of masculine and feminine traits and is the most adaptive social gender type [11]. The disease associated with social stigma is a more significant stress for people with high prevalence of masculine traits in social gender. For such people situations where they can't show the expected physical, intellectual and sexual advantage are highly stressful. Uncontrollable and unpredictable epileptic seizures can provide a complicated gender role conflict in such people. In contrast, avoiding and emotional coping strategies which are typical for people with dominating feminine traits result in a reduction of emotional distress, including the distress associated with disease. The life experience can make men and women change their stereotypic view on masculinity and femininity and correct their role behavior, which helps them adjust in social environment. From this point of view the high prevalence of feminine gender type in people with TLE could be a consequence of interaction between the subject and the disease.

As the social gender type is an internal guide to form the behavior from the childhood, it seemed logical for us to examine the relationship between aggressiveness profile and gender role behavior. The correlation analysis revealed different correlation 
Table 6. Correlation between gender role characteristics and aggressiveness, anxiety and depression level in patients with temporal lobe epilepsy.

\begin{tabular}{|c|c|c|c|c|}
\hline & & $\begin{array}{l}\text { Masculine } \\
\text { traits }\end{array}$ & $\begin{array}{l}\text { Feminine } \\
\text { traits }\end{array}$ & Bem index \\
\hline \multirow{2}{*}{ Assault } & Correlation, Pearson & 0.277 & 0.034 & -0.243 \\
\hline & Sig. 2-tailed & 0.097 & 0.842 & 0.147 \\
\hline \multirow{2}{*}{ Verbal hostility } & Correlation, Pearson & $0.371^{\star}$ & -0.040 & $-0.379^{*}$ \\
\hline & Sig. 2-tailed & 0.024 & 0.813 & 0.021 \\
\hline \multirow{2}{*}{ Indirect hostility } & Correlation, Pearson & 0.189 & 0.023 & -0.139 \\
\hline & Sig. 2-tailed & 0.264 & 0.892 & 0.413 \\
\hline \multirow{2}{*}{ Negativism } & Correlation, Pearson & $0.345^{\star}$ & -0.195 & $-0.439^{* *}$ \\
\hline & Sig. 2-tailed & 0.037 & 0.246 & 0.007 \\
\hline \multirow{2}{*}{ Irritability } & Correlation, Pearson & $0.341^{*}$ & -0.067 & $-0.342^{*}$ \\
\hline & Sig. 2-tailed & 0.039 & 0.695 & 0.038 \\
\hline \multirow{2}{*}{ Suspicion } & Correlation, Pearson & $0.420^{* *}$ & -0.060 & $-0.440^{* *}$ \\
\hline & Sig. 2-tailed & 0.010 & 0.724 & 0.006 \\
\hline \multirow{2}{*}{ Resentment } & Correlation, Pearson & 0.231 & -0.089 & -0.282 \\
\hline & Sig. 2-tailed & 0.168 & 0.601 & 0.091 \\
\hline \multirow{2}{*}{ Guilt } & Correlation, Pearson & -0.058 & -0.108 & 0.010 \\
\hline & Sig. 2-tailed & 0.731 & 0.526 & 0.954 \\
\hline \multirow{2}{*}{$\begin{array}{l}\text { Motor component of } \\
\text { hostility }\end{array}$} & Correlation, Pearson & $0.407^{\star}$ & 0.004 & $-0.376^{*}$ \\
\hline & Sig. 2-tailed & 0.012 & 0.980 & 0.022 \\
\hline \multirow{2}{*}{$\begin{array}{l}\text { Attitudinal } \\
\text { component of } \\
\text { hostility }\end{array}$} & Correlation, Pearson & $0.411^{\star}$ & -0.052 & $-0.425^{\star *}$ \\
\hline & Sig. 2-tailed & 0.012 & 0.761 & 0.009 \\
\hline \multirow{2}{*}{ Anxiety } & Correlation, Pearson & -0.104 & -0.167 & 0.012 \\
\hline & Sig. 2-tailed & 0.539 & 0.322 & 0.944 \\
\hline \multirow{2}{*}{ Depression } & Correlation, Pearson & -0.027 & 0.043 & 0.069 \\
\hline & Sig. 2-tailed & 0.873 & 0.800 & 0.685 \\
\hline
\end{tabular}

${ }^{*} \mathrm{p}<0.05,{ }^{* *} \mathrm{p}<0.01$.

pattern in people with TLE and healthy people. The correlation pattern of masculine traits and typology of aggressiveness in people with TLE demonstrates the move from overt to covert hostility.

\section{Conclusion}

The aggressiveness level of people with TLE is within social norm, but aggressiveness differs in male subpopulation of patients with TLE in comparison to healthy males. One explanation of phenomenological heterogeneity of aggressiveness in people with TLE and healthy individuals may be dominating of feminine social gender type in people with TLE. Perhaps the feminine gender type helps patient coexist with his illness. The correlations between gender role behavior and typology of aggressiveness can 
be considered as a target for psychotherapy.

\section{Conflict of Interest}

This research did not receive any specific grant from funding agencies in the public, commercial, or not-for-profit sectors.

\section{References}

[1] Piazzini, A., Bravi, F., Edefonti, V, Turner, K., et al. (2012) Aggressive Behavior and Epilepsy: A Multicenter Study. Epilepsia, 53, e174-e179. http://dx.doi.org/10.1111/j.1528-1167.2012.03643.x

[2] Bem, S.L. (1981) Bem Sex-Role Inventory: A Professional Manual. Consulting Psychologist Press, Palo Alto.

[3] Buss, A.H. and Durkee, A. (1957) An Inventory for Assessing Different Kinds of Hostility. Journal of Consulting Psychology, 21, 343-349. http://dx.doi.org/10.1037/h0046900

[4] Zigmond, A.S. and Snaith, R.P. (1983) The Hospital Anxiety and Depression Scale. Acta Psychiatrica Scandinavica, 67, 361-370. http://dx.doi.org/10.1111/j.1600-0447.1983.tb09716.x

[5] Bjelland, I., Dahl, A.A., Haug, T.T. and Neckelmann, D. (2002) The Validity of the Hospital Anxiety and Depression Scale: An Updated Literature Review. Journal of Psychosomatic Research, 52, 69-77. http://dx.doi.org/10.1016/S0022-3999(01)00296-3

[6] Crawford, J.R., Henry, J.D., Crombie, C. and Taylor, E.P. (2001) Normative Data for the HADS from a Large Non-Clinical Sample. British Journal of Clinical Psychology, 40, 429434. http://dx.doi.org/10.1348/014466501163904

[7] Kligman, D. and Goldberg, D.A. (1975) Temporal Lobe Epilepsy and Aggression. Journal of Nervous \& Mental Disease, 160, 324-341. http://dx.doi.org/10.1097/00005053-197505000-00002

[8] Lishman, W.A. (1998) Organic Psychiatry the Psychological Consequences of Cerebral Disorder. 3rd Edition, Blackwell Science, Oxford.

[9] Beghi, E., Spagnoli, P., Airoldi, L., Fiordelli, E., Appollonio, I., Bogliun, G., Zardi, A., Paleari, F., Gamba, P., Frattola, L. and Da Prada, L. (2002) Emotional and Affective Disturbances in Patients with Epilepsy. Epilepsy and Behavior, 3, 255-261. http://dx.doi.org/10.1016/S1525-5050(02)00008-2

[10] Masood, S. and Rafique, R. (2012) Neuropsychological Functions in Epilepsy Patients. Journal of Ayub Medical College Abbottabad, 24, 10-13.

[11] Small, A., Teagno, L. and Selz, K. (1980) The Relationship of Sex Role to Physical and Psychological Health. Journal of Youth and Adolescence, 9, 305-314.

http://dx.doi.org/10.1007/BF02087982 
Submit or recommend next manuscript to SCIRP and we will provide best service for you:

Accepting pre-submission inquiries through Email, Facebook, LinkedIn, Twitter, etc. A wide selection of journals (inclusive of 9 subjects, more than 200 journals)

Providing 24-hour high-quality service

User-friendly online submission system

Fair and swift peer-review system

Efficient typesetting and proofreading procedure

Display of the result of downloads and visits, as well as the number of cited articles

Maximum dissemination of your research work

Submit your manuscript at: http://papersubmission.scirp.org/

Or contactwjns@scirp.org 